\title{
Zeta potential of calcite-water interface: an improved model for high ionic strength conditions
}

\author{
MIFTAH HIDAYAT ${ }^{1,2}$, JAN VINOGRADOV ${ }^{1}$, PHILIPPE \\ LEROY $^{3}$, DAMIEN JOUGNOT ${ }^{4}$, JOS DERKSEN ${ }^{1}$, STEFAN \\ IGLAUER $^{5}$, DAVID VEGA-MAZA ${ }^{6}$ AND MOHAMMAD \\ SARMADIVALEH ${ }^{2}$ \\ ${ }^{1}$ University of Aberdeen \\ ${ }^{2}$ Curtin University \\ ${ }^{3}$ French Geological Survey \\ ${ }^{4}$ Sorbonne Université \\ ${ }^{5}$ Edith Cowan University \\ ${ }^{6}$ University of Valladolid \\ Presenting Author: r03mh18@abdn.ac.uk
}

The interfacial properties of the calcite minerals in contact with aqueous solution receives a lot attention in scientific community due to the abundance of calcite in soils and sediments and its geo-engineering applications, including enhanced oil recovery, groundwater resource management and $\mathrm{CO}_{2}$ geo-sequestration. For over a decade, several studies have been performed to model the electrochemical properties of the calcite-water interface using surface complexation models to predict the zeta potential, which is the electrical potential at the mineral surface. Most of them only work well for low ionic strength and simple brine compositions. The models consider each calcite surface site having an interaction with ions from the brine, which can be described using a surface complexation reaction and its equilibrium constant. This constant is then optimised along with the Stern layer capacitance to match the experimental zeta potential data which results in a constant capacitance value for limited range of low salinity. However, the modelled low concentration conditions are unrealistic of deep subsurface settings that tend to have high ionic strength and complex brine compositions. Therefore, understanding the electrochemical properties of the calcite-water interface at high ionic strength conditions is still an active area of research. In this study, we report the simulated zeta potentials using a new surface complexation model for a wide range of ionic strengths. We introduce a new modelling approach considering that some parameters can change with salinity. Furthermore, Pitzer database and theory are used in the model to accommodate for high ionic strength. We successfully match the simulated zeta potentials with the experimental data for three different carbonate rock samples. The computed electrolyte $\mathrm{pH}$ and concentration of all ions $\left(\mathrm{Na}^{+}, \mathrm{Ca}^{2+}, \mathrm{Mg}^{2+}, \mathrm{Cl}^{-}\right.$, and $\left.\mathrm{SO}_{4}{ }^{2-}\right)$ are validated against the experimental data. The results from our study significantly improve our understanding of calcite-water interactions for high ionic strength conditions. The implications of the findings from our study has a broad range of geoengineering applications such as oil recovery and underground gas storage. 